\title{
Impact of Hiv/Aids Morbidity on Households Economy in Malaysia
}

\author{
Khalid Ghailan (Corresponding author), A. Jusoh, M. Rizal, Sharifa Ezat, F. Ibrahim, Jalal Halil \& S. Aljunid \\ United Nation University, International Institute of Global Health, Malaysia \\ Tel: 603-9171-5372Ｅ-mail: khalid.ghailan@gmail.com
}

\begin{abstract}
Costs to mitigate HIV/AIDS outcomes and information on household socioeconomic impact in Malaysia are very limited, despite their importance to guide key policy decisions. The aim of this study is to identify the economic impact of chronic adult HIV morbidity, specifically to estimate the cost of care from households' perspective. Median out of pocket health expenditure per patient per year is RM1 080 representing $14.7 \%$ of patient's median income. (Note 1) Productivity loss due to absenteeism and inability to work were RM 900 and RM10 800 respectively. The overall HIV/AIDS related cost from a household economic perspective proved substantial in this analysis. It reached RM359 million representing $0.06 \%$ of Malaysian GDP in 2007. An important policy implication is to ensure proper resource allocation to manage and control HIV/AIDS, more investment on training and to ensure that households can support themselves without jeopardizing the wellbeing and future of other family members.
\end{abstract}

Keywords: Household socioeconomic impact, HIV/AIDS cost, Productivity loss

\section{Introduction}

Human Immunodeficiency Virus/ Acquired Immune Deficiency Syndrome (HIV/AIDS) is a major public-health problem worldwide. It affects mostly young people who are at the most productive part of life. Over half of the world's population, 3.2 billion of a total of 6.1 billion, live in the low and middle income countries of the Asia Pacific region. About 8 million adults and children are living with HIV/AIDS and more than a million have died. An estimated US\$ 5.1 billion was required to combat this disease in 2007 and that will rise at a cumulative annual rate of $40 \%$. This is substantial and must be faced seriously. (ADB/UNAIDS 2004) ${ }^{\text {a }}$ Rapid growth has been recorded in special populations such as injecting drug users (IDUs), commercial sex workers (CSWs) and mobile populations. The epidemic could be many times worse if a noticeable transition to the general population was established. (ADB/UNAIDS 2004) ${ }^{\mathrm{b}}$

The deterioration of the most productive segment of the population in society has remarkable implications for the economy and social structure of any nation, particularly those countries with single dominant formal industries such as tourism or agriculture. This threat negatively impacts the GNP, export-earning and public-revenue generation, and investment, especially in education. The most immediate effect is the depletion of government resources as substantial funds are diverted to the health sector. Literally it is a global economic challenge and like other South East Asian countries, Malaysia is not beyond the dispute. (UNDP 2005)

The most important component to be examined, in terms of societal economic impact, is HIV/AIDS related outof- pocket expenditures and productivity loss for patients and households. The WHO reports that in middle-income and low-income economies out-of-pocket spending is often second only to government expenditures in terms of size and share of total health care costs. In the absence of social health insurance, out-of pocket spending varies from one-third and two-thirds of the total health expenditure. Inequalities in financial burdens of the health care system are most likely to appear in out-of-pocket spending (Shengelia 2003). Ronald Horstman. (2007) has shown that from the Latin American and Caribbean Region tried to predict out-of-pocket expenditures on HIV/AIDS on the basis of macro indicators. (Ronald 2007)

These out-of-pocket expenditures can be highly erratic as demand for health care is unpredictable and any significant share of out-of-pocket expenditure can have a disruptive effect on household consumption and ultimately an impoverishing factor. (ADB/UNAIDS 2005)

Productivity loss is a significant component of the societal costs of a disease, beyond that of health care resources. The term productivity costs has been defined as "the costs associated with lost or impaired ability to work or engage in leisure activities due to morbidity" by the US Panel on Cost-Effectiveness in Health and Medicine. (Pedram 2004) 
To assess economic impact of disease, the human capital approach has been widely used. This method estimates productivity losses from illness or injury as measured by income forgone due to morbidity, disability and mortality. (Olufunke 2009)

The importance of productivity loss estimation can be shown in an example of cost-effectiveness analysis of HAART in HIV-infected patients. It has been shown that the inclusion of productivity gains due to improved health status of the patients would substantially increase the economic attractiveness of HAART. (Sendi 1999) When productivity gains were included in a broader societal perspective, HAART was a cost saving strategy; when the analysis was limited to health care costs, the cost-effectiveness ratio was not so high. However, in the South East Asian region, including Malaysia, few data are available about the ability of HIV-infected patients to work, which determines their potential level of productivity and possible associated factors.

Lubeck and Fries, estimated a mean of 25.4 disability days per year for asymptomatic individuals and 123.55 disability days per year for people who are symptomatic patients. This study considered reduced productivity due to disability results both from short-term absenteeism and from below-average or suboptimal performance. (Lubeck 1992)

Around the corner in Thailand, a household impact survey involving 116 households with recent experience of an HIV/AIDS-related death in 5 high prevalence districts within Chiangmai province in northern Thailand. Key findings included: "The loss of income from the diseased family member was found to be largest part of the economic costs of an HIV/AIDs related death and HIV/AIDS medical costs were approximately six months of average total household income. Direct and indirect costs associated with HIV/ AIDS deaths were more substantial than non HIV/AIDS deaths within the groups surveyed". (Sukhontha 2001)

Patients who were once considered permanently disabled or in a terminal phase of AIDS are now experiencing remarkable improvements in health and may be able to remain at work or return to work after periods of illness. Although the inclusion of lost productivity will remain an important factor in assessing the impact of HIV infection, it may become less dominant. (C. Daniel 2000)

Malaysia is home to one of the fastest growing AIDS epidemics in the East Asia and Pacific region. Between the first detected case in 1986 and 2008, 84,630 infected cases were registered, with $0.5 \%$ prevalence among the age-group 15-49 years. Some women and children have been notified that they are infected with HIV; while 11,234 have died of AIDS. (MOH 2009)

In most of the countries of the region, the epidemic has not entered the broader community, so its effects are unlikely to be evident in many national indicators such as macro-economic growth, or in the business and education sectors. However, social and economic impact of the disease starts from the individual level, then through household into the country's economy.

Evidence based on research in the area of HIV/AIDS socio economic impact is desperately needed for better resource mobilization, advocating acting partners, as well as for enforcing policies and implementing care and support programs.

This study aimed to estimate the economic impact of chronic adult HIV morbidity on households and examine how they cope with the situation by measuring patients spending on HIV/AIDS care, along with productivity losses. It tries to identify characteristics that may influence patient productivity changes and explore the implications of the findings for policies to mitigate the impact of HIV/AIDS on households and communities.

A household is defined as person or persons who have made arrangements, individually or in groups, for providing themselves with food and other essentials within the same living quarters for more than 16 days. (Department of statistics Malaysia 2007)

\section{Methodology}

This study is cross-sectional in nature, and included 300 patients between 18 to 56 years of age. The country was stratified into four zones, namely the North Coast, South Coast, East Coast and West Malaysia, represented by the states of Kedah, Johor, Kelantan, and Selangor respectively. Figure (1) The selection of states and number of participants from each state was according to the geographical distribution of infection, the density of infected population, and forms of economic activities in the area, as per HIV/AIDS surveillance data up to the year 2007. Figure (1)

It is claimed by HIV/AIDS specialists that more than $90 \%$ of the states' HIV/AIDS cases are channeled to referral hospitals because of free treatment availability, counseling and HIV /AIDS specialist's follow-up services. Respondents have been selected from outpatient HIV/AIDS clinics. 
According to latest statistics of reported HIV infections and AIDS 2001-2007 in the selected states, the required sample of patients was apportioned based on the density of cases in each zone. 40 patients were selected from Hospital Sultanah Bahiyah- Kedah, 100 patients form Hospital Sultanah Aminah- Johor, 60 patients from Hospital Raja Perempuan Zainab II- Kelantan, and 100 patients from Sungai Buloh Hospitals-Selangor, using a systematic random sampling method. About 3 - 8 patients a week were studied for a period of 5 months because HIV/AIDS patients should follow up with the clinic every 3 to 4 months. The selection of respondents was adjusted by gender and ethnicity. Excluded were those who had the disease less than one year, those below 18 and above 56 years old, and non Malaysians.

Respondents have gone through detailed interviews using a structured questionnaire designed for this study. Out of pocket expenditure was quantified by finding patients' spending on transportation, fees for services, medication, traditional medicine and other expenses.

Measuring productivity loss in this population was based on patients' inability to work and days of absenteeism for those still working. Median monthly income before contracting the infection was used as a benchmark.

Although we conducted the interview with patients but, we consider this study is household perspective study because our objective was centralized around patient him/her self, assuming patient is fully aware of the economic changes in the household. Nevertheless, the findings from this study should be considered with some limitations; such as the cost of careers who provide home based care was not estimated.

This study was started in August 2007, collecting retrospectively six months data only from the respondents in order to minimize possible recall bias.

Data is descriptively presented by using spss statistical program. Factors associated with ability to work were analyzed in a multivariate ordinary logistic regression (proportional odds) model.

Training for the interviewers, single administration of data and involving counselors from each state were strictly adhered to in order to insure reliability of our tool.

\section{Results}

\subsection{Socio demographic impact}

The respondents were selected to reflect the main Ethnic groups (Malay, Chinese and Indian) as well as male to female ratio, with slightly more female respondents in order to better reflect the socioeconomic impact on females' life in this country. Table (1)

Household headed by fathers were about $56.9 \%$, the rest were headed by mothers, elder brothers or sisters or grandparents. More patients were from households headed by non fathers than those from traditional families. When infected fathers were excluded, Fisher's Exact Test showed the difference was statistically significant $(\mathrm{P}<$ $0.001 \mathrm{df}$ (1) for $\mathrm{n}=297$ ). Table (2)

Comparing the marital status before and after the detection of disease showed over $13 \%$ of married couples got divorced. When patients CD4 count fell below 200 cells $/ \mathrm{mm}^{3}$ and some of them developed AIDS, the divorce rate increased to one third of all married patients.

The mean number of children for married, widowed or divorced patients $(\mathbf{6 1 . 7 \%}$ of the total number of respondents) is 2.09 children \pm 1.57 ranged between 1 to 8 children per patient. The 2.09 children per patient are vulnerable to becoming orphans. Figure (2)

It is very obvious that HIV is hitting almost every single possible occupation and no career is isolated. Table (3) The disease is seriously threatening the transition from risk groups such as unemployed people and sex workers into normal population. The percentage of infected salesmen, laborers, managers, unemployed as well as mobile workers is alarming. (Note 2)

This study showed that the Median No. of infected patient in one household is 1patient, with the range the of between 1 to 5 patients under the same roof. This profoundly affected household income and expenditure which resulted in not having enough money for necessities. To mitigate the high expenditure of the affected household income; food, quality of accommodation, qualifying plans and entertainment are respectively affected.

Rural/urban distribution and internal migration such as moving from urban to rural, or the other way around, because of the disease was also investigated as a potential source of economic loss. However it was not noticeable and the ratio remains similar 52:43 Urban to Rural before and after detection. It was observed though that some ran away from their families to stay alone or with friends. 


\subsection{Cost of HIV/AIDS from household perspective}

\subsubsection{Direct cost (out of pocket expenditure)}

The total estimated median of "out of pocket expenditure" per year is RM $1080(500-16480)$ which is almost $14.7 \%$ of patient's median income, without considering the income change due to productivity loss. The above mentioned out of pocket expenditure for HIV/AIDS would seem vividly higher if we compare it with RM 192 that the average household spends on health according to Malaysian national statistics for 2007. (Department of statistics Malaysia 2007) Patients were asked to list down their out of pocket expenditures related to HIV/AID in the past six months. In addition to cost of transportation and hospital charges the major cost components in out of pocket expenditure were on health food supplements and traditional medicine which reflects clearly that there is a lack of knowledge in this particular area and therefore needs the counselors to pay more attention.

The difference in terms of out of pocket expenditure between working status groups was only in the range of \pm RM 40 and ANOVA showed that the difference between groups (currently working, currently not working, not working before and after) Figure (4) was not statically significant, which means even those non working groups are also maintaining the average expenditure from various sources.

The most influential factors associated with increasing out of pocket expenditure were; gender, age, working status, income per month, and latest CD4 count. Interestingly, only CD4 appears to be statistically significant associated. ANCOVA has been used to control other factors while examining the association between out of pocket expenditure and CD4 count as shown in the following table. Table (3) (Note 3)

\subsubsection{Second: Indirect cost (Productivity Loss)}

In Malaysia majority of the cases contracted the disease through IVDU, the misperception among the public that HIV/AIDS affected community is not economically productive, therefore the economic impact of HIV/AIDS should not be a countable matter.

This study demonstrated that $41.1 \%$ of the patients were heading their households. The overall working status for all the participants are presented in Figure No.5 that implies, only $15.5 \%$ were economically non-active as they were not working before and after the infection was detected. Whereas $46.5 \%$ are still working and $35.7 \%$ have (or has been) stopped working due to HIV/AIDS. Figure (4)

It is clearly shown that health related reasons for stopping work is $73 \%$ for those patients who stop working due to the infection, whereas it represent only $41 \%$ in the non economically productive group (not working before and after the detection). Figure (5)

It is featured that the respondent's median income per month was around RM 900 in healthy-life period. Therefore HIV/AIDS was negatively impact on their productivity and then household income due to cassation of work or increased median number of days of absenteeism to 20 days a year due to attending clinic, admitted to ward and staying home because of illness. Table (4) The estimated median annual productivity loss per patient was RM 10800 for those who have totally stopped working and RM 900 the cost of absenteeism for those who are still working. This would correspond to a total productivity loss calculated on national level from the following formula:

Total estimated productivity loss in $\mathrm{RM}=\mathrm{N} \times 46.5 / 100 \times 900+\mathrm{N} \times 35.7 / 100 \times 10800$

$$
=\mathrm{RM} 287,364,839.4 \text { per year }
$$

$\mathrm{N}:=67,234$ The number of registered HIV/AIDS Patients, excluding deaths up to 2006 and new cases in 2007. $(80,938-(10,334-1,179)-4,549=\mathbf{6 7}, \mathbf{2 3 4})$

46.5/100: The percentage of working patients

900 RM: The Median cost of absenteeism a year (Note 4)

35.7/100: The percentage of patients who stop working

10800 RM: The Median cost of stop working a year

Sources: AIDS/STI Unit, Ministry of Health \& Resource Center. Malaysian AIDS Council end of 2007.

It estimated that HIV/AIDS households in the country are losing $\mathbf{4 6 . 8} \%$ of the total income due to HIV/AIDS morbidity and the related inability to work or absenteeism from work. The total estimated income a year for all HIV/AIDS patients (excluding those non productive patients (15.5\%) is RM 613,577,484 while total estimated loss of productivity is RM 287,364,839.4. The percentage of unemployment among PLWHA before HIV detection was $\mathbf{1 5 . 5 \%}$; after detection it rose to $\mathbf{5 1 . 2 \%}$. 
Factors such as knowledge about HIV/AIDS and being forced to quit a job showed no statistical significant association when tested against the ability to work. On the other hand, statistical significant associations were found between the mode of transmission, latest CD4 count and HIV treatment status, according to the model presented in Table (5). Model fitting test LR showed sig. $<0.001$ at $\mathrm{df}=30$ which means that the variables in the model contribute considerably.

The national estimated cost of HIV/AIDS from a household perspective is:

$\mathbf{O O P}_{\text {exp }}+\mathbf{P L}=72,612,720.00+287,364,839.40=\mathbf{3 5 9 , 9 7 7 , 5 5 9 . 4}$

OOP is: Out of Pocket expenditure per patient estimation for the year 2007

PL is: Productivity loss due to absenteeism and stopping work due to HIV/AIDS related reason

\section{Discussion}

Out of pocket health expenditure is found to be relatively high, although it is known to us that health care services in Malaysia are heavily subsidized by the government. Unfortunately it was shown that much is spent on health food supplements and traditional medicine which reflects a clear lack of knowledge concerning treatment and the need to focus on counseling, not only to avoid cost escalation, but also to prevent its possible side effects and interference with their ARV regimen.

HIV/AIDS related debt was hard to assess. Our respondents were sensitive in sharing the details of their personal finance, although it was very clear in many individual cases as well as the overall average, expenditures related to HIV/AIDS were exceeding their income. Household members might have borrowed money for daily necessities and health care, others tended to consume their savings or sell assets. In a study conducted by Sukhontha in Thailand, she found that for the household to cope with HIV illness, it used whatever savings available, sold their assets, cut their consumption and obtained support from extended family members. Various strategies were used to maintain family productivity including increasing family members' workload, hiring laborers and withdrawal of children (especially girls) from school. (Sukhontha 2006)

Productivity loss was the main influence on household income through PLWHA job losses or absence from work. The number of children who are vulnerable to becoming orphans are also apt to quit education system and enter early child hood employment. Therefore the free medical and financial support for the needy should use multi dimensional selection criteria to reach the poorest section of households with PLWH. It is important also to identify methods to increase coverage for these vulnerable groups.

Our findings suggest that resource-allocation decision makers would benefit from improved understanding of the full economic impact of chronic disease. This highlights the fact that in medical decision-making, whenever possible, both direct and indirect costs should be considered to visualize the economic consequences for specific intervention.

Analyzing the key components of high out of pocket expenditure is proposing more investment in training for health care counselors should be given priority on the other hand we should think seriously of better risk pooling mechanisms as financial systems to bring down the share of out of pocket expenditures and to prevent catastrophic impact of increased costs; higher public contribution should be maintained.

\section{Conclusions}

This paper highlighted how chronic HIV morbidity impacts household income. It has illustrated substantial consequences on household labor supply and family income. It shows a $0.06 \%$ loss of Malaysian GDP as a direct and indirect outcome of HIV/AIDS. Other family member's productivity loss was not included in this analysis.

This study has important policy implications concerning households with PLWH and the need to support themselves and meet their medical care expenses without jeopardizing the wellbeing and future of other family members.

\section{Recommendations}

A form for socioeconomic impact monitoring needs to be used for HIV/AIDS patients while they are having their regular follow up visits to health care facilities. It will help:

To monitor changes accurately

To enhance the relationship with health care service providers and increase treatment adherence

To facilitate social support services to be directed to the needy. 
To possibly help in protecting patients from serious psychological disorders.

This study could help risk groups as well as the young adults in general to be more aware of disease consequences. Families and communities should understand their social responsibility as HIV impacts negatively on the whole community rather than the individual punishment. This understanding will help community members to modify their behavior toward HIV patients and their families as a part of a commitment to create a safer community. It could be the first step to minimize stigma attached to HIV/AIDS and to reduce anxiety and fear.

Proper counseling for partners and household members is equally as important as patients' counseling. It should be regular and ongoing in order to avoid multiple psycho-socio-economic complications.

Further research is needed to estimate the cost of productivity loss to employers, including diminished quality of work, sick leave, health insurance premiums, and other frictional costs incurred by employers (e.g., hiring and training temporary employees).

\section{References}

ADB/UNAIDS. (2004) ${ }^{\mathrm{b}}$ Socio economic impact of HIV/AIDS in Asia and the Pacific, current and future scenarios. The ADB/UNAIDS Studies Series. Paper IV.

ADB/UNAIDS. (2004) $)^{\text {a }}$ Funding required in confronting the HIV/AIDS Epidemic in the Asia and Pacific Region. The ADB/UNAIDS Studies Series. Paper 1

Bank Negara Malaysia. (2010). Exhange rate - Historical Lookup. [Online] Available: http://www.bnm.gov.my/index.php?ch=12\&pg =629 (May12, 2010).

C. Daniel MuUins, PhD, 1 George Whitelaw, RPh, 2 Jesse L. Cooke, I and Eduard J. Beck, PhD 3. (2000). Indirect Cost of HIV Infection in England, Clinical Therapeutics, 22, 1333-1345.

Department of statistics Malaysia. (2007). Yearbook of Statistics, ISSN 0127 - 2624, page 244.

Department of statistics Malaysia. (2007). Yearbook of Statistics, ISSN 0127 - 2624, page 247.

Lubeck DE \& Fries JE. (1992). Changes in quality of life among persons with HIV infection. Quality of Life Research Journal, Volume (1) (6) 359-366.

Ministry of Health Malaysia. (2009). AIDS in Malaysia [Online] Available: http://www.unicef.org/malaysia/hiv_aids_overview.html (Jun6, 2010).

Olufunke A. Alaba and Olumuyiwa B. Alaba. (2009). Malaria in Rural Nigeria: Implications for the Millennium Development Goals. African Development Revie, Volume 21, Issue 1, Pages: 73-85.

Pedram Sendi, Fabian Schellenberg, Chaiwat Ungsedhapand, Gilbert R. Kaufmann, Heiner C. Bucher, Rainer Weber. (2004). Productivity Costs and Determinants of Productivity in HIV-Infected Patients. PubMed, (5): 791-800.

Ronald Horstman. (2007). Can we predict out-of-pocket expenditures on HIV/AIDS on the basis of macro indicators? Evidence from the Latin American and Caribbean Region. UNFPA/UNAIDS/NIDI, Resource Flows Project. [Online] Available: www.resourceflows.org/index.php?module=uploads\&func=download.

Sendi PP, Bucher HC, Harr T, et al. (1999). Cost effectiveness of highly active antiretroviral therapy in HIV-infected patients. Swiss HIV Cohort Study. AIDS. Volume (13) page 1115-1122.

Shengelia B. et al. (2003). Beyond Access and Utilization: defining and Measuring Health System Coverage. In: Murray C.J.L. and Evans D. (2003). Health System Performance Assessment: Debates, Methods and Empiricism. WHO, Geneva, 2003, chap 20. [Online] Available: http://whqlibdoc.who.int/publications/2003/9241562455_(part4)_(chp16-24).pdf, (Jul23, 2008).

Sukhontha Kongsin. (2001). Conducting a Household Survey on the Economic Impact of Chronic HIV/AIDS Morbidity in Rural Thailand : Methodological Issues. Journal of Health Science Vol. 10 No. 2 April - June 2001. [Online] Available: http://pubnet.moph.go.th/hto/vol10no2/special4.pdf.

Sukhontha Kongsin. (2006). THE ECONOMIC IMPACT OF HIV/AIDS MORBIDITY ON HOUSEHOLDS IN UPPER-NORTH THAILAND: PHAYAO CASE STUDY, Deputy Dean for finance and Budgeting, and Assistant Professor in Health Economics, Department of Public Health Administration, Faculty of Public Health, Mahidol University. HIV/AIDS consultative meeting for south east Asia, KL, PHD Thesis. 
UNDP. (2005). Malaysia achieving the new millennium development goals, successes and challenges. Published by the United Nations Country Team, Malaysia January, ISBN 983-3055-03-6, [Online] Available: http://www.epu.jpm.my/New\%20Folder/publication/UNDP1.pdf. (May11, 2005).

UNFPA/UNAIDS/NIDI. Resource Flows Project, Netherlands Interdisciplinary Demographic Institute. [Online] Available: www.resourceflows.org, (Jan15, 2010).

Source of Maps:

FULL GOSPEL BUSINESS MEN'S FELLOWSHIP, MALAYSIA 2009. Type: 220KB JPG, Size: $460 \times 272$, Source: www.fgb.com.my/History.html, sited in 6-2009

\section{Notes}

Note 1. $1 \mathrm{RM}=0.291$ USD (Bank Negara 2010)

Note 2. Mobile workers include_(drivers, fisherman, reporters, tour guides and ethnic dancer.

Note 3. Based on Table 2

a. Adjusted mean using ANCOVA controlling for age, gender, monthly income and working statues (Sig. difference between group (1) \& (3) P value $<0.023$ (71.9 - 1570.9))

b. Bonferroni adjustment for $95 \%$ confidence interval for difference (pair wise comparisons)

d. Assumptions: form leven's test and plotting residuals vs predicted; Overall model fitness and groups equal variance was checked. Plotting Residual vs each covariate showed non linearity with covariates. Finally normality was clearly shown by drawing the histogram although in this scenario while sample size is more than 30 , normality tend to be not an issue. Patients representing various severity stages of the disease based on CD4 count were normally distributed.

Note 4. Cost per day for those working patients in RM has been calculated by dividing total income a month by 20 working days a month (excluding weekends and public holidays) to estimate the cost of each day of absenteeism. 
Table 1. Describing the socio demographic characteristics of our respondents

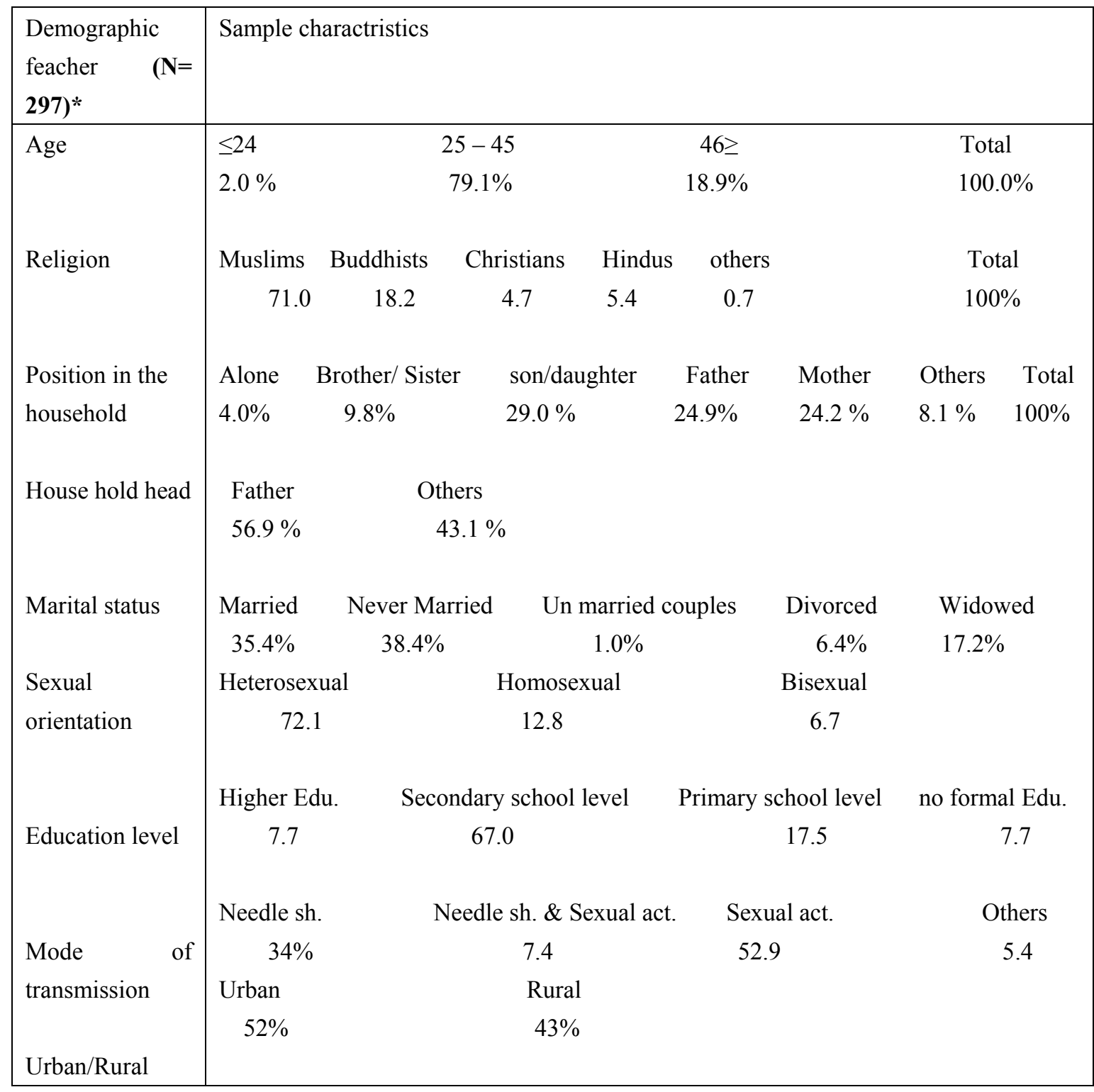

$*(N=300$, 3are missing cases, the total cases including in the analysis $=297)$

Table 2. Of patients from households headed by father vs. headed by others

\begin{tabular}{lccc}
\hline \multicolumn{1}{c}{ Household headship } & Infected father & others infected & \multicolumn{1}{c}{ Total } \\
\hline Headed by father & 60 & $\mathbf{1 0 9}(\mathbf{4 2 \%})$ & 169 \\
Headed by others & 3 & $\mathbf{1 2 5 ( 3 7 \% )}$ & 128 \\
Total & 63 & 234 & 297 \\
\hline
\end{tabular}

$\chi^{2}(1, \mathrm{n}=297)=47.9, \mathrm{p}<0.0001$ 
Table 3. Out of pocket expenditure vs. severity level using CD4 count indicator

\begin{tabular}{|c|c|c|c|c|c|}
\hline CD4 count & $\mathrm{n}$ & $\begin{array}{l}\text { Adjusted Mean } \quad(95 \% \\
\text { CI)a }\end{array}$ & Adjusted mean diff.(95 CI)b & F test a $(\mathrm{df})$ & $P$ value a \\
\hline (1) & 90 & 2100 & \multirow{3}{*}{$\mathrm{P}$ value $<0.023(71.9-1570.9)$} & \multirow[t]{3}{*}{$4.6(3,283)$} & \multirow[t]{3}{*}{0.003} \\
\hline $201-500$ & 121 & 1455 & & & \\
\hline $500<$ & 86 & 1279 & & & \\
\hline
\end{tabular}

Table 4. Estimated cost of absenteeism and stopping work per year

\begin{tabular}{|l|l|l|l|l|}
\hline Description & Mean & Median & Minimum & Maximum \\
\hline Income/Month before (RM) & 1079 & 900 & 200 & 4400 \\
\hline No. of Days of absenteeism/ 6 months & 11 & 10 & 2 & 60 \\
\hline *Cost per Day (RM) & 56.61 & 45 & 10 & 220 \\
\hline Total productivity loss a year due to absenteeism per patient & 1245.42 & 900 & 90 & 14700 \\
\hline Total productivity loss a year due to stopping work per patient & 12155.84 & 10800 & 2400 & 44400 \\
\hline
\end{tabular}

Table 5. Factors Associated with Ability to work after HIV/AIDS detection

\begin{tabular}{|l|l|l|l|l|}
\hline Variable $\quad(\mathrm{n}=297)$ & Adj. O R & $(95 \%$ CI OR $) \mathrm{a}$ & $\chi^{2}$ stat $(\mathrm{df})$ & P value a \\
\hline Mode of transmission & & & $17.076(6)$ & 0.009 \\
$-\quad$ needle sharing & 3.569 & $(1.750-7.280)$ & & $<0.001$ \\
$-\quad$ needle sharing\& Sexual & 3.431 & $(1.105-10.649)$ & & $<0.001$ \\
$-\quad$ others & .580 & $(.112-3.012)$ & & $<0.517$ \\
$-\quad$ sexual & 0 & - & & - \\
\hline $\begin{array}{l}\text { CD4 count } \\
<200\end{array}$ & 5.604 & $(2.149-14.618)$ & & $<0.001$ \\
$201-500$ & 1.29 & $(0.536-3.128)$ & & $<0.565$ \\
$500>$ & - & - & & \\
\hline HIV treatment & & & & \\
No & 2.6285 & $(1.303-5.300)$ & & 0.007 \\
Yes & - & - & & \\
\hline $\begin{array}{l}\text { Gender } \\
0 \text { Female }\end{array}$ & 1.928 & $(0.850-4.374)$ & & \\
1 Male & .982 & $(.982-.982)$ & & \\
\hline
\end{tabular}




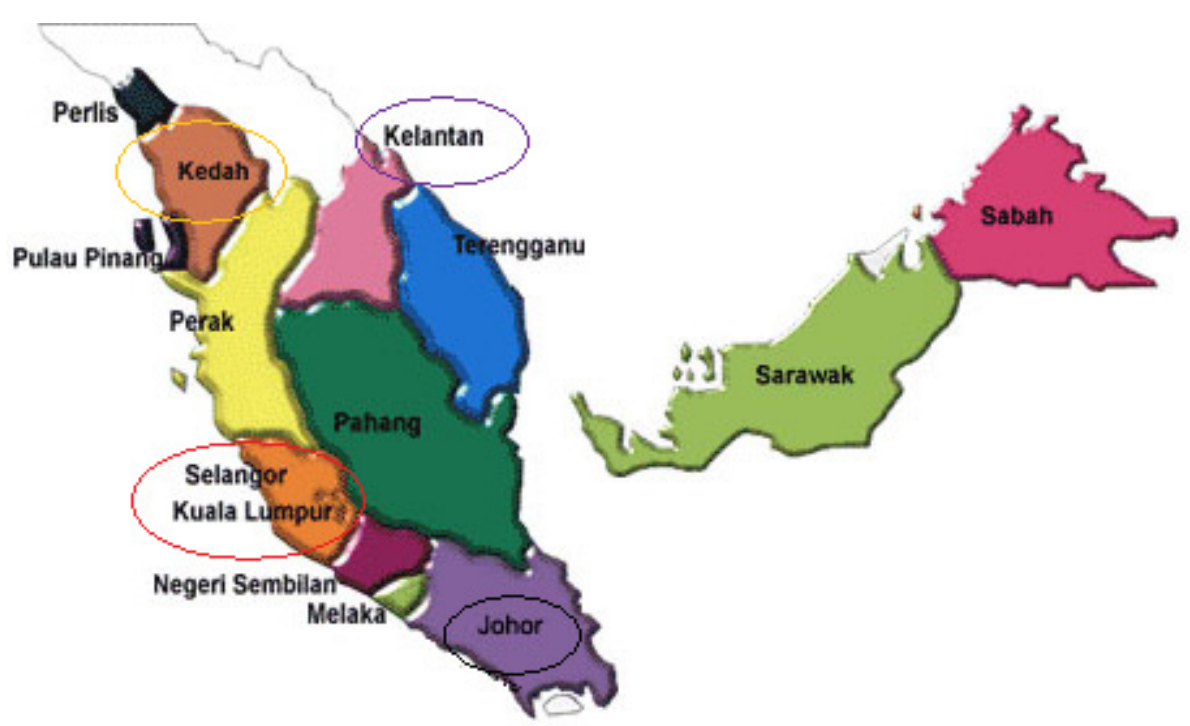

Figure 1. Map of Malaysia

Source: FGBMF Malaysia 2009

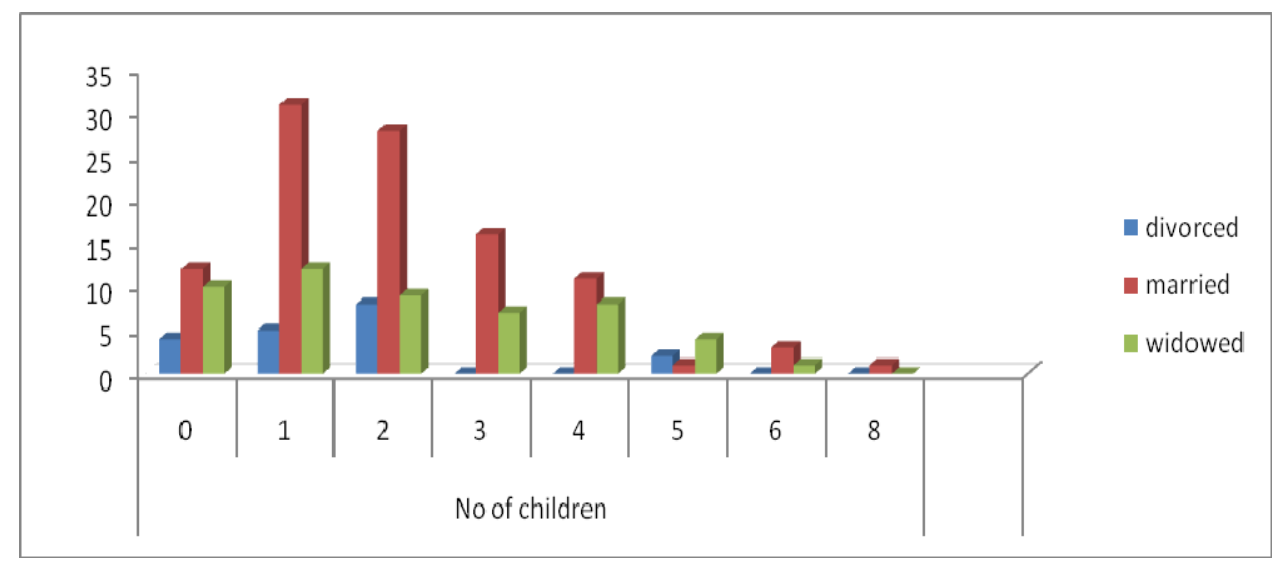

Figure 2. No. of children per married HIV/AIDS patient 


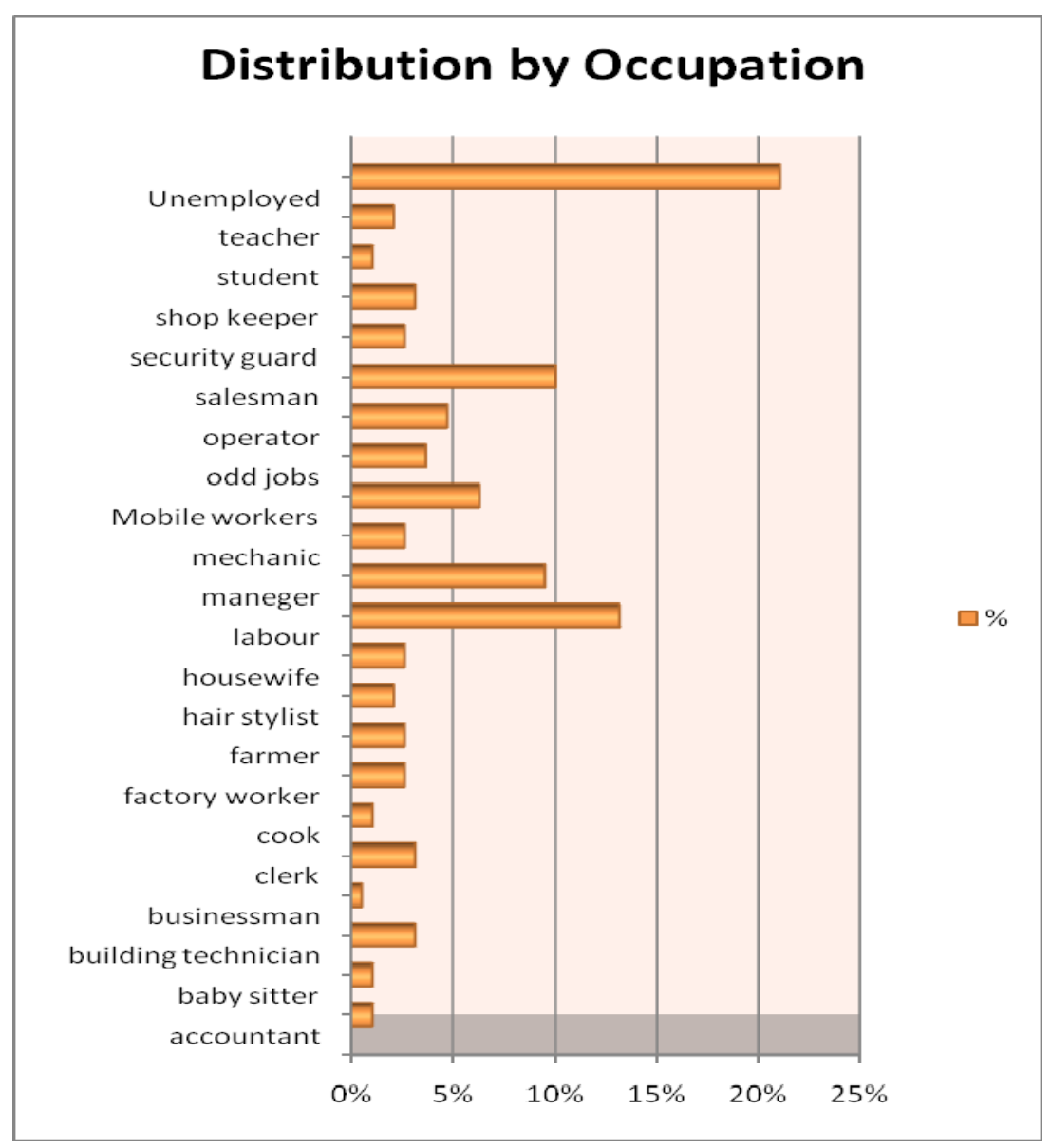

Figure 3. Respondents distribution by occupations

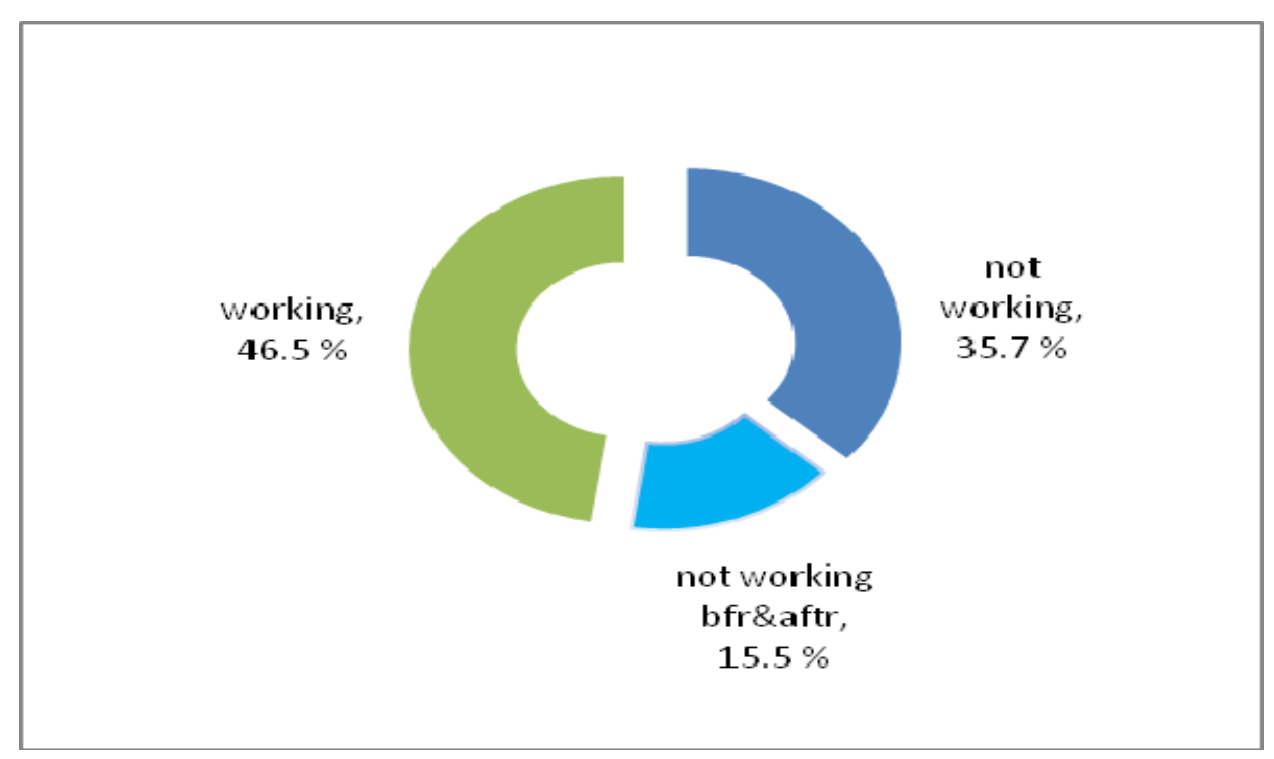

Figure 4. Distribution of patient's as per current working statues 


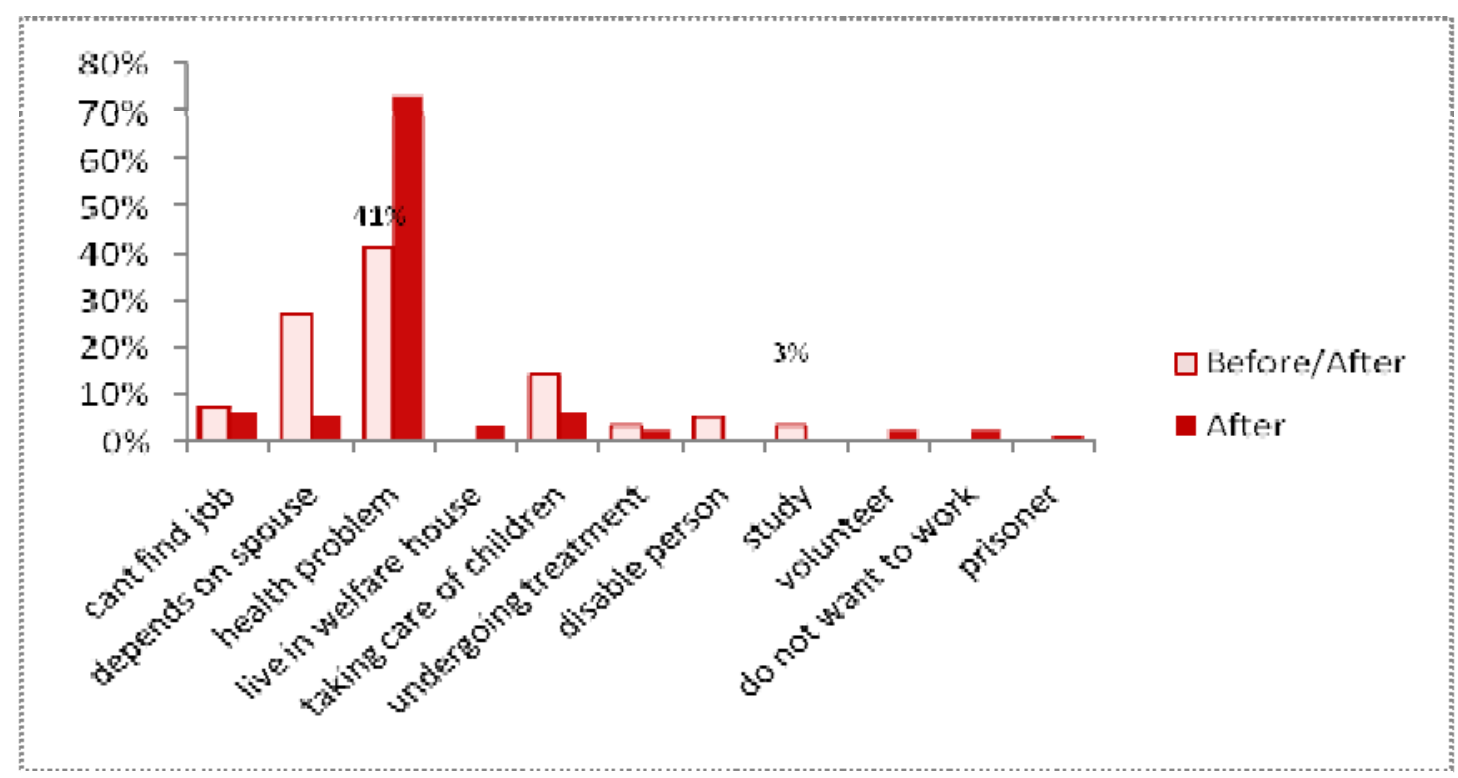

Figure 5. Comparing reasons of not working between the two categories; those not working before and after vs. not working after the detection 